\title{
カノニカル・モンテカルロシミュレーションによる 液体表面の構造解析と蒸発熱の推定
}

\author{
盛岡良 雄* \\ 広島県立大学７ 727-0023 広島県庄原市七塚町 562
}

(Received June 18, 2002; Accepted July 16, 2002)

\begin{abstract}
液体表面の構造を俯瞰的に観察できるようにするため, カノニカル $(N V T)$ 集団によるモン テカルロ (MC) シミュレーションを試みた。新たに提案したDTMC (Dual Translation Monte Carlo) 法を用いれば，これまで実行の難しかった分子局在系についてもNVTMCが可能となる。バルク 液相から表面分子への相互作用を近似するため固定床モデルを提出し，兴の有効性を確かめた。 これは, 吸着系への適用なども期待できる汎用的なモデルとなっている。さらに，シミュレー ションの妥当性を各種物性值で直接検証できるようにするため, 沸点と液体密度の実測値をも とに，実用的なLennard-Jones（LJ) パラメータを決定した。ArやKrなどの1 原子分子について， 蒸気圧の温度依存から推定された蒸発熱は実測值とよい一致を示した。
\end{abstract}

キーワード: 液体表面の構造, NVTMCシミュレーション, DTMC法, 固定床モデル, LJパラメータ

\section{1 ・はじめに}

液体の表面は, 均一な構造の液相と蒸気相, 弚し て両者の間を介在する薄い遷移層とからなっている。 液相と蒸気相とでは分子密度に1000倍以上もの違い があるが, 乥れらが, わずか数分子程度の厚さの遷
移層を介し近接していると考えられる。このような 表面遷移層内の分子の集合構造を解明することは， 気液平衡現象のほかにも，液体の表面張力や毛管現 象，さらには固体表面における蒸気の吸着現象など を理解する上からも重要である。

Lennard-Jones (LJ) 流体に, 分子動力学 (MD) 法やモンテカルロ (MC) 法を適用して表面張力を 求め, 実測值と比較することで, 気液界面の構造を 調べようとする試みはここ 20 年ほどの間に数多く

*morioka@bus.hiroshima-pu.ac.jp 
行われている[1]。しかし，結果は報文によってまち まちであり，実測値との一致もよくない。㫕の理由 として, HolcombらはLJポテンシャルのcut-off距離 , セルの大きさ, さらには液相部分の厚さなどの影響 について議論している[1]。

しかしこの他にも，液体表面のように分子集合が 偏在して粗密の複合構造を形成しているような系に ついて, 通常の均一系に対すると同樣の分子シミュ レーションを適用してよいのかという問題がある。 さらに, これまでの研究で用いられてきたモデルの セル構造やLJパラメータの妥当性についても，十分 な検討はなされていない。

ここでは，ArやKrの希ガス分子を例にとり，こ れまでほとんど議論されることのなかった，液体密 度や蒸気圧, さらには蒸発熱などの実測データとの 定量的な比較を行いながら新たなシミュレーション の方法を探る。また, 続報では表面張力や吸着現象 などの実測結果をも比較対象として, 液体の表面構 造を解明する上での分子シミュレーションの可能性 について論ずることにする。

\section{2 . 理論}

\section{1.表面領域の熱力学}

液体表面のように集合状態の偏在した構造体を熱 力学的に取り扱うために, 古くから二つの近似法が 提案されている[2]。Guggenheimの方法とGibbsの方 法である。MC法による分子シミュレーションにお いても，これらの近似法は光れ光れ $\mu V T($ グランド・ カノニカル) 集合およびGibbs集合として継承されて いる。

Guggenheimの近似では，蒸気相と液相の間に有 限の厚さの第 3 相 , すなわち表面相を考える。これ により，表面遷移層は仮想的な均一構造体として表 現されることになる。

$\mu V T$ 集合による分子シミュレーションでは，こ の表面相領域に注目し，この部分をひとつの集合と してあつかう[3]。乥して, 外部 (蒸気相と液相) か らの分子の出入りを考えながらシミュレーションを 行い, 平衡状態における集合内分子の構造を決定す るのである。

一方，Gibbsの近似では遷移層領域の存在谷のも のを無視する。液体の表面は, 液相と蒸気相の間に ある，厚みのない単なる幾何学的な分割面としてと らえられる。乥して, このために生じた, 分子数な どの示量変数の過不足の矛盾は, 新たに表面過剩の
概念を導入することで解消された。

Gibbs集合による分子シミュレーションにおいて も分割面の近似を導入している[4]。ただし, 表面過 剰の概念は用いず，分割面の位置の移動や，2相間 での分子のやりとりで相間の平衡を決定している。

ここで注意しないといけないのは,$\mu V T$ V Gibbs のいずれの集合によるシミュレーションも，表面遷 移層の構造の問題には触れていないことである。す なわちこれらのシミュレーションでは, 液体表面の 構造に関する知見は得られないことになる。

\section{2 . 2 . DTMC法の提案}

液体表面の構造を解明するためには，遷移層につ いての近似をいれず，液相から蒸気相にかけての全 表面領域を俯敢的にとらえたシミュレーションが必 要となる。光れには, MC法の原点に立ち返り，NVT (カノニカル)集合を用いるのが最良の方策である。

しかし, 液体表面のような偏在分子系に対し, 通 常のNVT集合によるMCシミュレーションを行うと， 平衡到達が極端に遅くなることが知られている。光 の結果, 粒子数か数百個以上の大きさの系では害行 が事実上不可能となる。

これは , メトロポリスの方法を実行するときの， 粒子の微小変位量の選び方に問題が生じるためであ る。計算量を減らすための最も効率的な微小変位量 は, 粒子間の平均距離すなわち粒子密度に依存する ことが知られている。ところが, 偏在分子系では分 子密度の極端に異なる部分が系内に複数存在してい る。このため, シミュレーションの過程で微小変位 量をランダム発生するとき，1種類の最大変位幅だ けでは, セルの全域を担うのに無理が生じるのであ る。

本報ではこの問題を解決するため，Dual Translation Monte Carlo (DTMC) 法を提案し, 光の有効 性を検証することにした。これは，大小 2 種類の最 大変位幅を用意し，これらを一定の割合でランダム に用いながら各粒子の微小変位量を決定し, 通常の NVTMCシミュレーションを実行していく方法である。 実行の詳細については次節で説明する。

\section{3. シミュレーションの方法}

\section{3 . 1 . セルの構造}

液体表面の分子シミュレーションでは,バルク液 相から表面分子に働く大きな相互作用を近似的に取 
り入れるため, セルの構造に特別な工夫が必要とな る。従来は, この目的で 2 種類の方法が用いられて きた。これらを「壁法」と「薄膜法」とよゔことに する。

壁法[5]では , セルの底にバルク液相の代わりと なる仮想的な平板状の壁をおく。分子に働くポテン シャルは壁表面からの距離のみに依存するものとし， 例えばYoungらの示したLennard-Jones $(9,3)$ ポテン シャル[6]を用いて算出する。この方法の利点は,プロ グラムに多少の修正を加えるだけでシミュレーショ ンが実行できることである。しかし, 液相の密度分 布に, 本来はないはずの周期構造か現れるという致 命的な欠陥を持っている。

薄膜法 $[7,8]$ では, セルの中央に液体の薄膜をお き，膜の両側面を気液界面とみなしてシミュレーシ ヨンを行う。周期境界条件を適用すれば安定なシミ ユレーションを実行できるが, 膜の厚さをどの程度 に取るかという点に問題が残る。また, 薄膜モデル では, 著者らの意図している吸着現象への適用など の展望が望めない。

乥こで本報では，図１に示すような直方体セルを 用いたシミュレーションを実行することにした。

図において,水色の球がシミュレーションの対象 となる流体分子群, セルの底部に青色で示した球が

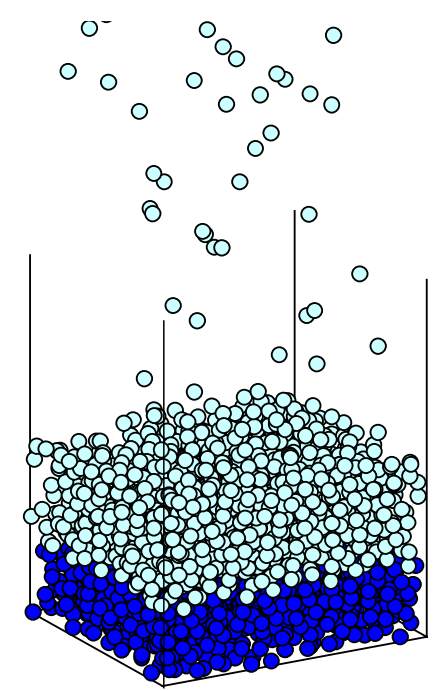

Fig. 1 An example of snapshot in the vicinity of the liquid surface.

Blue: fixed bed; Turquoise: fluid.

分子を底に引きつけておくための仮想的な固定床粒 子群である。この固定床がバルク液相の代わりを果 たすことになる。本報で提出したこの方法を以下で は「固定床法」と呼ぶことにする。なお，典型的な
シミュレーションでは, 流体分子と固定床粒子の総 数を 2,600 個程度とした。

固定床粒子どうしのポテンシャルとしては, 流体 分子と同じものを用いた。乥して, シミュレーショ ンに先立ち，あらかじめ固定床粒子だけを対象とし たモンテカルロ試行を実行し定常配置を得た。なお， このとき固定床領域を単独のセルとみなして周期境 界条件を適用している。

実際のシミュレーションは,水色の流体分子につ いて行うのだが, この間, 固定床粒子は動かさず固 定したままとする。ただし，相互作用については、 流体分子どうしだけでなく固定床粒子との間につい ても考慮する。

流体分子のシミュレーションにおいて,セルの水 平方向には通常の周期境界条件を適用したが, 垂直 方向では次のようにした。すなわち、分子の移動軌 跡の計算では周期条件を適用するが，固定床内への 侵入は禁止した。一方、ポテンシャルの計算には周 期条件を適用しなかった（適用しても，流体分子が 固定床の両面に対称に凝集するだけで, プロフィー ルを始めとした結果にはまったく影響しない。ここ では解析の便のため周期条件をはずしている）。

なお，予備試行の結果，固定床として $2 \sigma$ 以上の 厚さがあれば, シミュレーションの結果にほとんど 影響を及ぼさないことが確かめられた。

ところで,図1では上方部の描画を省略している が, 実際のセルの形状は極端な縦長である(セルの 代表的な大きさは20× $\left.20 \times 400 / \sigma^{3}\right)$ 。これは，気相 密度から系の蒸気圧を算出しようとしたためである。 気相を理想気体と仮定すれば, 弚の平衡蒸気圧は分 子密度から直接算出できる。算出精度を上げるため には気相の体積を大きくとる必要があって，縦長の セルとしたのである。このように特異な形状のセル ではあるが，DTMC法の効果もあって，平衡到達に は何らの支障も生じない。

\section{3．２．DTMC法によるシミュレーション}

DTMC法では,大小 2 種類の最大変位幅を用いる。 ひとつは系の全域にわたり分子の移動を起こさせ るための「大変位」である。本報では光の最大変異 幅の垂直成分として，セルの各辺の半分の長さを光

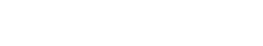

一方, 主に液相内での分子の動きをシミュレート するためには「小変位」を行う。このときの最大変 異幅としては, 通常の液体のMCシミュレーション に用いられると同程度の $0.2 \sigma$ を採用した。

シミュレーションにあたっては,小変位での試行 のあいだに大変位試行をランダムに混ぜて実行する。 あらかじめ, 大変位試行の混合割合を $0 \%$ から $50 \%$ 
の範囲で変えてみたが , 平衡への到達速度は大きく 変化するものの, 最終結果には違いのないことが確 かめられた。以下では, すべてのシミュレーション について大変位試行の混合割合を $20 \%$ とする。

図 2 には ,シミュレーションの進行にともなう平 衡蒸気圧の変化の実例を示した。なお，詳細は 4 節 で述べるが，ここでいう蒸気圧は沸点温度 $T_{B}$ におけ る蒸気圧 $\left(=\right.$ 大気压 $\left.p_{0}\right)$ に対する相対値として表 してある。図は, シミュレーション開始前の分子の

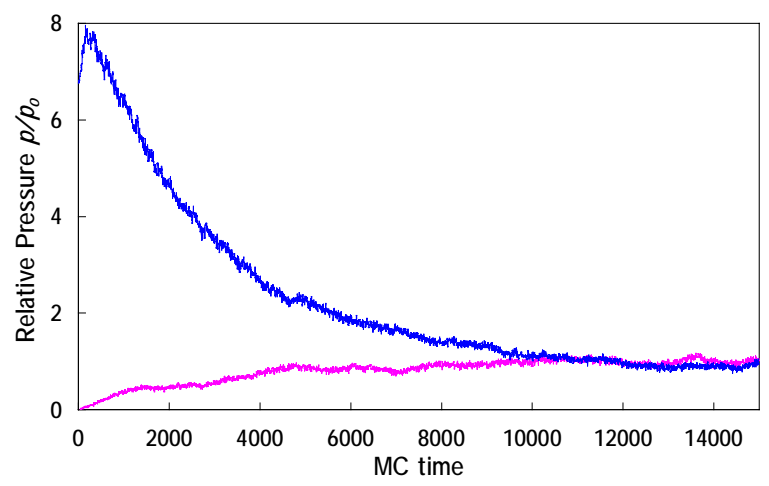

Fig.2 Effect of initial arrangement of $\mathrm{Kr}$ molecules on a course of the DTMC simulation.

初期配置を大きく変えた 2 回の試行を比較した結果 である。初期配置の違いによらず，いずれの曲線も 速やかに同一の蒸気圧值に収束していることがわか る。これは, DTMC法がよく機能しており, シミュ レーションによって正しい平衡状態が得られている ことを示す。

以上をまとめると ,シミュレーションにおけるデ 一タの採取手続きは次のとおりとなる。

ステップ1：固定床, 流体ともに液体密度に等 しくなるよう分子をランダムに初期配置。

ステップ2：固定床分子について, 少なくも 10,000 MC時間のMC試行を行い定常状態にする。

ステップ3： 流体分子について，30,000 MC時 間以上のDTMC試行をアイドリングとして実行。

ステップ 4： 流体分子について5,000 MC時間 のDTMC試行を行い, 密度分布や蒸気圧のデータを 採取。

なお, 偏りのないデータを得るため, 乱数を変え た同一条件のシミュレーションを $3 〜 5$ 回繰り返し た。また, DTMC試行が定常に達したことは蒸気圧 の変化によって確かめた。

\section{4 . LJパラメータの決定}

流体分子ならびに固定床粒子の分子間相互作用 としては，12-6 Lennard-Jones ポテンシャル式(1)を 用いた。

$$
u\left(r_{i j}\right)=4 \varepsilon\left[\left(\frac{r_{i j}}{\sigma}\right)^{-12}-\left(\frac{r_{i j}}{\sigma}\right)^{-6}\right]
$$

ここで， $\mathcal{E}$ との両パラメータについてである が，これらの值は文献によってもまちまちである。 しかも，実際にはこれらの值のわずかの差によって， シミュレーションで得られる平衡蒸気圧や液相密度 に大きな違いが現れる。著者らの目的は, シミュレ ーションによって蒸発熱や表面張力を求め実測值と 比較検討することにある。炎のためには現実の界面 現象によく適合した妥当なLJパラメータを使用する 必要がある。

ここではDTMCによる予備試行によって妥当なLJ パラメータを決定することにした。すなわち，各種 の液体について文献值の充実している 液体密度 $\rho_{L}$

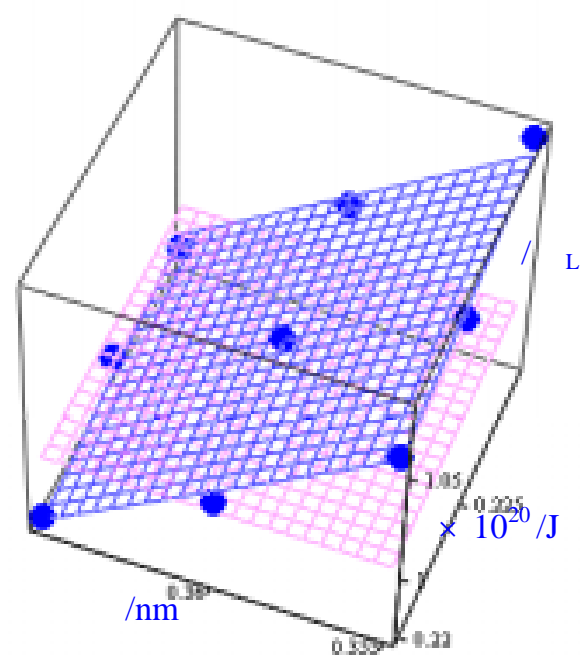

Fig. 3 Regression analysis to determine LJ parameters from the liquid densities simulated by DTMC for $\mathrm{Kr}$.

と $T_{B}$ の值をもとに最適な $\mathcal{E}$ との值を決定しよう とするのである。

図 3 は, 温度 $T_{B}$ において, $\mathcal{E}$ と $\sigma$ の值をいくつ か変えてシミュレーションを実行し，乥れ光れにつ いて得られた液相部密度の值をプロットしたもので ある。なお, 液相部密度はシミュレーションの密度 分布のデータから求め, $\rho_{L}$ に対する相対値として 表してある (図4 参照)。図からもわかるように， 青丸で示した各データは平面上に並ぶのので, 重回帰 
Table 1. Properties of each molecule

\begin{tabular}{l|c|c|c}
\hline \multicolumn{1}{c|}{ Properties } & $\mathrm{Ar}$ & $\mathrm{Kr}$ & $\mathrm{N}_{2}$ \\
\hline Boiling point / K & 87.28 & 119.74 & 77.35 \\
Liquid density at b.p. / $10^{3} \mathrm{~kg} \mathrm{~m}^{-3}$ & 1.393 & 2.41 & 0.808 \\
LJ parameter $\sigma / \mathrm{nm}$ & $0.3404^{*}$ & $0.3628^{*}$ & $0.3604^{*}$ \\
LJ parameter $\in \boldsymbol{k}^{-1} / \mathrm{K}$ & $118.13^{*}$ & $164.49^{*}$ & $101.11^{*}$ \\
Dimensionless boiling point & $0.739^{*}$ & $0.728^{*}$ & $0.765^{*}$ \\
Dimensionless liquid density & $0.828^{*}$ & $0.827^{*}$ & $0.813^{*}$ \\
Heat of vaporization / $\mathrm{kJ} \mathrm{mol}^{-1}$ & 6.52 & 9.03 & 5.58 \\
Heat of vaporization / $\mathrm{kJ} \mathrm{mol}^{-1}$ & $6.7^{*}$ & $9.0^{*}$ & $5.8^{*}$ \\
\hline
\end{tabular}

* Estimated by the DTMC simulation. Nitrogen is approximated as 1-centered molecule.

分析により平面の方程式を決定することができる。 次いで, 蒸気圧についても同樣の解析を行い, $\rho / \rho_{L}=1$ かつ $p / p_{0}=1$ となるように $\mathcal{E}$ との最 適値を決定した。解析は $\mathrm{Kr}, \mathrm{Ar}$ およ゙1中心近似 の室素について行ったが, 結果を表 1 にまとめて示 した。なお，いずれの重回帰分析でも，決定係数は $R^{2}>0.95$ となり, シミュレーション結果を平面で 近似することの妥当性を示している。

表 1 には参考までに これらのLJパラメータを用 いて算出した無次元の沸点と液体密度をも示した。 いずれの値も，分子によらずほぼ同程度の大きさと なっているが, 必ずしも一定值であるとはいえない。 無次元データによるシミュレーションだけで, 分子 の種類によらない一般論的な結論を導き出すことに は注意の必要なことがわかる。

以下のシミュレーションにおいては，表 1 のLJ パラメータを用いる。また, 相互作用はすべての分 子間について評価し, cut-off 距離による計算の省略 はしないことにした。

\section{5 . 結果と考察}

\section{5 . 1 . 液体表面の構造}

図1に示したのは、シミュレーションの結果得ら れたスナップショットの一例である。図は沸点温度 におけるKrの例であるが , ここではモデルの特徵を 明らかにするため, 典型的なシミュレーションにく らべ厚みの大きな固定床の場合について示している。
図から, 液相より蒸気相にかけての広い領域の表面 構造が俯瞰的にとらえられていることがわかる。こ れはカノニカル集団を用いた本報の成果であり，こ れまでの $\mu V T$ 集合やGibbs集合によるシミュレーシ ヨンでは得られなかったものである。今後, 液体表 面だけでなく吸着現象の解明にも役立つものと期待 される。

さらに定量的な議論を行うため,典型的なシミュ レーション結果から得た密度分布を图 4 に示す。図

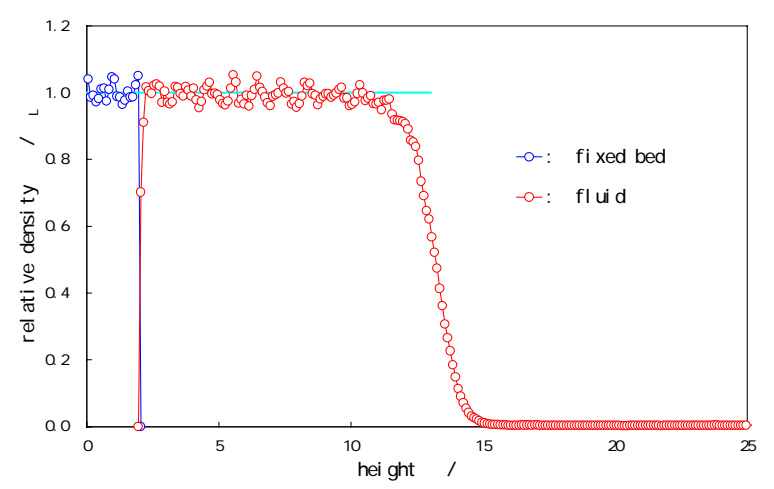

Fig.4 Density profile obtained by the DTMC simulation for Ar at boiling point.

の横軸はセルの垂直方向の高さであり，縦軸はバル クの液体密度で規格化した分子密度である。

液相部分の密度プロフィールは, 固定床と連続的

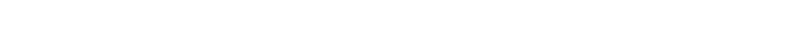
定值 (水色の水平線) を示している。すなわち, こ の部分ではバルクの液相と同樣の構造が実現されて いると考えられる。

また 液相から気相に向かっては密度が急激に低 


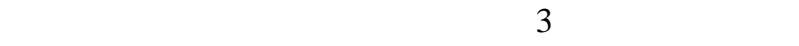
とがわかる。遷移層の形状は対称ではなく, 液相側 のほうがややなだらかに変化している。

図では, 気相部分のプロフィールの大部分を省略 したが, 弚の密度は均一であり, 理想気体と仮定す れば気圧を求めることができる (もちろんこの場合 は大気圧が得られることになる）。

ここに例示したのはArについての結果であるが， Krや1中心近似の窒素についても同樣の結果が得ら れた。さらに, 固定床の厚さや, セルの底面積 , 流 体分子の個数などをさまざまに変えてみたが, 表面 遷移層のプロフィールには影響しないことが確かめ られた。

ところで, 従来の壁モデルを用いたバルク液相の 近似法では, 密度分布に不当な周期性の現れるのが 避けられなかった[5]。しかし，ここで提出した固定 床モデルでは, 図 4からも明らかなように, 液相領 域における密度分布の周期性発現が完全に抑えられ ている。したがって，このモデルは固定床を固体に 置き換えることで, 今後吸着系の構造解明などにも 利用できる汎用的なものとなっている。

\section{5 . 2 . 蒸発熱の推定}

本報によって,カノニカル集団を用いたシミュレ ーションが可能になり, さらに沸点温度と液体密度 の実測值に基づいたLJパラメータを決定することが できた。乥こで，光れらの結果の妥当性を検証する 目的で, 蒸気圧の温度依存を調へ，乥こから蒸発熱 を推定してみることにした。

图5に示したのは，Krについてのシミュレーショ ン結果である。沸点を中心に温度をいくつか変化さ せ, 得られた平衡蒸気圧をClapeyron-Clausiusの関係 に従ってプロットしたものである。なお，蒸気圧は 大気圧 $p_{0}$ で規格化してある。

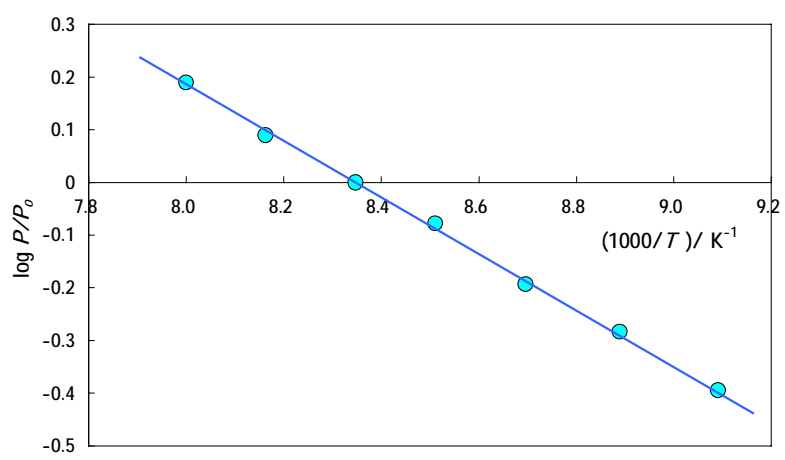

Fig. 5 Clapeyron-Clausius plot obtained by the DTMC simulation for $\mathrm{Kr}$.
プロットは良好な直線関係を示しているので,关 の勾配から蒸発熱の推定值を算出することができる。 Arや 1 中心近似の窒素についても同樣の結果が得ら れるので, 乥れらをまとめて文献による実測值とと もに表1に示した。

表 1 によれば, いずれの蒸発熱の推定值も, 弚れ

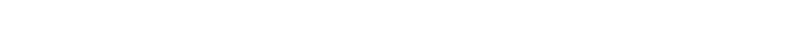
こで提唱したDTMCシミュレーションが, 液体表面 における実際の現象をよく近似・表現していること を示すとともに，新たに決定したLJパラメータの有 効性を示すものである。

表1のなかで特に注目したいのは窒素の結果であ る。ここでは, 1 中心近似による窒素を用いてシミ ユレーションを行ったのだが, 光れでも蒸発熱の推 定值と実測值の一致は満足すべきものである。

多孔体の細孔構造の解析のためには，窒素の吸着 等温線の用いられることが多く, 著者らは今後, 室 素吸着についてのシミュレーション的研究を進めた いと考えている。光の際，1中心近似でも妥当な結 果が得られるならば、計算量の大幅な節約ができる ことになる。

\section{6 . まとめ}

本報で提示したDTMC法は,手法としてはきわめ て単純なものであるが, 局在分子系の分布構造を妥 当に推定できる有用な方法であることが確かめられ た。従来多用されている $\mu V T M C な と ゙ に$ 代わって， 吸着系の解明などにも活用できるものと期待される。

LJパラメータについては，これまで, 実測状態方 程式から算出された値を兴のまま用いることが多か った。しかし，この值の適否はシミュレーションの 結果に直接かかわるものであり，採用には十分な注 意が必要である。

固定床によるバルク液相の置き換えは,わずかの 計算量の増加で高精度の近似をもたらすことがわか った。このモデルは，吸着現象における固体表面の 代わりとしても有望である。

\section{文献および注}

[1] C. D. Holcomb, P. Clancy, and J. A. Zollweg, Mol. Phys., 78, 437-459(1993).

[2] 小野 周 ,“表面張力”, 第1章 ,共立出版, 1980.

[3] D. J. Adams, Mol. Phys., 29, 307-313(1975).

[4] A. Z. Panagiotopolos, Mol. Phys., 61, 813-819(1987).

[5] G. A. Chapela, G. Saville, and J. S. Rowlinson, Faraday Disc. Chem. Soc., 59, 22-28(1975). 
[6] D. M. Young and A. D. Crowell, "Physical Adsorption of Gases", Chap.1, Butterworth, London, 1962.

[7] M. J. P. Nijmeijer, A. F. Bakker, C. Bruin, and J. H.
Sikkenk, J. Chem. Phys., 89(6), 3789-3792(1988). [8] Li-Jen Chen, J. Chem. Phys., 103(23), 10214-10216 (1995). 


\title{
Monte Carlo Simulation of the Liquid Surface by the Simple Canonical Ensemble, and Estimation of the Heat of Vaporization
}

\author{
Yoshio Morioka ${ }^{*}$ \\ Hiroshima Prefectural University, Shobara, Hiroshima, 727-0023, Japan
}

\begin{abstract}
The canonical ensemble was used to simulate the vapor/liquid interface, in order to visualize the whole configuration of molecules in the system. Although it had previously been difficult to apply the NVTMC to an extremely localized system such as liquid surface because of the slow convergence, the DTMC (Dual Translation Monte Carlo) method proposed in this paper permitted a significant simulation. The effectiveness of a fixed bed model, that approximates the entire interaction force from the bulk liquid onto the molecules making up the liquid surface, was confirmed. This is a multipurpose model that can be applied to the adsorption system as well as to liquid surface. In addition, we determined two parameters in the Lennard-Jones potential for Ar, $\mathrm{Kr}$, and 1-centered nitrogen by pilot simulations based on real experimental values, for liquid density and boiling point. Heat of vaporization was estimated using these new LJ parameters for each molecule during the DTMC simulation, and the results showed good agreement with experimental data in the literature.
\end{abstract}

keywords: Structure of liquid surface, NVTMC simulation, DTMC simulation, Fixed bed model, LJ parameters

\footnotetext{
*morioka@bus.hiroshima-pu.ac.jp
} 